\title{
Restauro e "restauros" das obras arquitetônicas do século 20: intervenções em arranha-céus em confronto
}

Simona Salvo*

(Tradução: Beatriz Mugayar Kühl**)

\section{Resumo}

O artigo trata de problemas de intervenção na arquitetura contemporânea, questão que se coloca há pelo menos vinte anos mas que ainda não atingiu maturidade suficiente. Analisando as várias orientações teóricas e as modalidades de intervenção, a autora evidencia uma tendência difusa a refazer, antes que conservar, tendo-se por conseqüência o cancelamento de partes e de materiais autênticos, e uma progressiva perda de memórias arquitetônicas.

Contrapõe a essa prática difusa, a obra realizada no arranha-céu da Pirelli em Milão, em que se percorreu o caminho da intervenção conservativa e que demonstrou concretamente, na prática, que o restauro da arquitetura moderna pode ser enfrentado com os instrumentos oferecidos pelo campo disciplinar da restauração, que exige que se enfrente a questão com rigor teórico, metodológico e científico. Para tanto, é necessário um processo crítico árduo, através do qual se desenvolva uma atenção "conservativa" adequada e uma abertura criativa para o projeto - que não é a livre transformação ou inovação, mas é interna à obra -; e que de fato possibilite a conservação da obra e sua transmissão ao futuro, como quer a restauração. Através de suas análises, a autora mostra ainda que negar a possibilidade de conservação do moderno é injustificado e sem fundamento teórico.

Palavras-chave: Preservação da arquitetura moderna. Teoria da restauração. Arranha-céus.

Restoration modalities in 20th century architecture: confronting skyscrapers interventions

\section{Abstract}


The article addresses the problems of interventions in contemporary architecture - an issue that has emerged at least twenty years ago, without reaching sufficient maturity so far. Analyzing different theoretical orientations and intervention modalities, the author identifies a diffuse tendency to re-make rather than maintaining and, as a consequence, the suppressing of built parts and of authentic materials, as well as a progressive loss of architectonic memories.

In opposition to this diffuse praxis, the work realized in the Pirelli skyscraper in Milan followed a conservative approach of intervention, concretely demonstrating that the restoring of modern architecture can be faced with the tools offered by the disciplinary field of restoration - that is to say, with the utilization of theoretical, methodological and scientific rigour. For that matter, an arduous critical process is required, through which an adequate conservative approach can develop, as well as a creative opening for the project, making the preservation of the building and its transmission to the future possible, according to the restoration principles. Through her analysis, the author shows that to deny modern heritage the possibility of a conservative approach is unjustifiable and devoid of theoretical basis.

Key-words: Preservation of modern architecture. Theory of restoration. Skyscrapers.

A questão de como intervir com fins "conservativos" na arquitetura contemporânea já se coloca há vinte anos; apesar da longa experiência operacional e das numerosas oportunidades para realizar comparações, ainda não se atingiu uma maturidade suficiente que permita falar de verdadeira restauração. Por outro lado, é possível fazer um balanço das orientações teóricas e das modalidades de intervenção, prevalentes e preferidas, nas obras de arquitetura moderna e contemporânea, que denotam uma marcada tendência a refazer, antes que conservar (1).

Na práxis, de fato, distinguem-se duas posturas principais: para as obras de valor reconhecido, ademais pertencentes à produção arquitetônica da primeira metade do século 20 , nota-se uma inclinação difusa e decidida para a repristinação à l'identique [ao idêntico]; para as obras mais recentes, que remontam ao segundo pós-guerra, 
mantidas numa espécie de limbo entre o repertório formal ainda palpável e os chamados monumentos de reconhecido valor histórico-arquitetônico, são muito comuns as intervenções de contínua e desenvolta substituição. No conjunto, portanto, seja no caso em que a obra - considerada mais um símbolo do que um objeto real -, viva no tempo e no espaço, seja reconduzida a um estado o mais similar possível ao original, seja no caso em que um edifício, do qual não se percebe ainda o valor cultural, seja mantido em perfeita eficiência por razões contemporâneas e conjunturais - de ordem formal, funcional, social ou econômica -, continua-se, ainda assim, a refazer antes que conservar; em ambos os casos tem-se como conseqüência, através do cancelamento de partes e de materiais autênticos, uma indubitável e progressiva perda de memórias arquitetônicas recentes.

Tal situação pode ser julgada como resultado da propensão a considerar a intervenção nas obras recentes como questão diversa do verdadeiro restauro que, de algum modo seria reservado ao antigo, somada a um aprofundamento históricocrítico, voltado à produção arquitetônica do século 20, ainda imaturo. Parece, com efeito, difusa e compartilhada - mas não, certamente, provada - a convicção de que as obras modernas não sejam restauráveis por causa de sua consistência material, muito diversa daquela das obras antigas, para as quais se desenvolveu toda a prática da conservação. Apesar do restauro ser, por princípio, um ato de cultura, que apenas na sua aplicação prática passa a se adequar ao objeto, muitos tendem a isolar o patrimônio recente da esfera da conservação e do restauro, fazendo dele, ao contrário, uma questão à parte e acreditando que, de vez em vez, deva ser enfrentada, selecionando a perspectiva disciplinar mais "consoante" ao caráter da obra, seja ele formal, construtivo, estrutural ou tecnológico; deriva disso que a intervenção nas obras de arquitetura do século 20 se está tornando um terreno de embate entre arquitetos "compositores", historiadores e tecnólogos que reivindicam, cada um deles, uma autoridade específica, enquanto, segundo a aproximação tradicional, o caminho a seguir deveria ser comum e compartilhado, enfrentado com o auxílio de competências múltiplas.

A maior parte das intervenções feitas nas obras do movimento moderno declara ter intenções filológicas apenas por princípio, enquanto, de fato, se concretiza através de operações de pura repristinação, voltadas a recuperar a imagem primeira, como 
difundida através das revistas daquele tempo, mesmo a custo de anular a autenticidade material da obra e de cancelar, desse modo, seu valor e os traços de sua incipiente historicidade. Essa tendência - que nasce na Europa setentrional, mas que foi exportada e aceita quase por todas as partes, especialmente nos países industrializados onde se propagou o international style, sem uma revisão séria reportava-se à especificidade material e construtiva da arquitetura moderna e à convicção, infundada, mas plenamente acatada, que no mundo da criação artística a revolução industrial tenha aberto uma fenda intransponível - nos materiais, nas formas, nas soluções construtivas e estruturais - a ponto de tornar inaplicáveis os princípios e métodos do restauro tradicional. Segundo alguns, a essência frágil, serial e efêmera do moderno, responsável por ter, no passar dos anos, corroído e consumido o significado dos objetos fundamentados no princípio de "novidade", implicaria necessariamente o abandono do respeito pela autenticidade material e a adoção de um aleatório conceito de "autenticidade da imagem" - ou de um ainda mais perigoso princípio de "autenticidade conceitual" - que a intervenção deveria recuperar integralmente, reconduzindo o objeto ao seu estado figurativo original. $O$ caráter físico da produção moderna é, desse modo, acolhido segundo uma acepção prevalentemente negativa, como um desacerto a ser corrigido e não como um valor a ser tutelado: a característica serial do novo é, com efeito, interpretada como falta de originalidade; a reprodutibilidade do produto industrial, como perda da condição de raridade e unicidade; a intencional transitoriedade, como oposição à duração no tempo congênita ao novo; o experimentalismo, como fonte de erros e falta de domínio na construção. Ao contrário, segundo a chave de leitura que oferece a mais amadurecida reflexão sobre o restauro, exatamente esses elementos representam o caráter precípuo da produção artística dessa época e deveriam, teoricamente, inspirar específica cautela e cuidado conservativo.

Os resultados das intervenções, ademais, demonstram que se privilegia a figuração da obra - em geral idealizada - em detrimento de sua efetiva realidade, mas não por causa de sua condição material, e sim pelo desconforto imposto pela demasiado breve perspectiva temporal que separa o objeto do observador contemporâneo, impedindo que este último perceba o distanciamento histórico que, mesmo sendo mínimo, existe. Uma "constrição cronológica" que, talvez, também por causa de uma resistência inconsciente em aceitar o envelhecimento de objetos pensados para 
resistir no tempo e apreciados porque visivelmente novos, induz a manter novo, o novo, e a considerar as obras do século 20 como modelos ainda utilizáveis e, portanto, a serem conservados isentos de qualquer traço de uma histórica "corrupção" material. Em relação às diversas condições em que se desenvolve a intervenção, configuram-se assim diferentes posturas repristinatórias que, nos casos mais comuns, são de tipo pseudo-filológico ou de atualização tecnológica.

No caso de intervenções em obras mais recentes, ao contrário, aos possíveis e ainda inexplorados valores do objeto se antepõem de modo mais declarado as exigências contemporâneas, sejam elas de uso, formais, funcionais, econômicas ou sociais. A casuística demonstra que as intervenções mais freqüentes oscilam, indo: da demolição, justificada de variadas maneiras, ao abandono do edifício, com as relativas conseqüências deletérias; do exercício de uma manutenção inconsciente, à adequação às normas conduzidas sem atenção para com qualidade da obra existente; das desenvoltas operações de restyling [re-estilização], aos refazimentos de variados gêneros e extensão. Na maior parte dos casos, a ausência de respeito pela identidade do objeto se deve à falta de consciência de seu valor, que permaneceu sem o reconhecimento da historiografia tradicional e da apreciação comum.

Parece, portanto, que raramente possam ser definidos como "restauros" as intervenções até hoje feitas em obras do século 20; demonstra-o a excepcionalidade e o caráter refinado da operação executada nas fachadas do arranha-céu Pirelli (2), em especial se confrontada com outras intervenções feitas em arranha-céus coetâneos (Figuras 1-3).

O aspecto mais problemático e interessante dessa intervenção se refere à recuperação dos perfis de alumínio anodizado que compõem as fachadas contínuas do edifício, juntamente com os revestimentos de pastilhas cerâmicas. Após uma análise preliminar sobre o estado de conservação dos elementos - depois de se ter descartado a hipótese de substituir os velhos perfis, ainda em condições excepcionalmente boas -, por causa de seu valor documental, tecnológico, construtivo e material, percorreu-se o caminho da intervenção conservativa. Para a ocasião, estudou-se um método experimental eficaz para reanodizar e retificar os 
perfis, permitindo salvar a quase totalidade das partes metálicas. A operação, conduzida tendo-se máximo cuidado com a conformação "historicizada" das superfícies e com pleno respeito pela autenticidade dos materiais e das características técnicas da fachada, permitiu manter o sistema construtivo original, introduzindo somente algumas pequenas modificações, necessárias para garantir o desempenho e a funcionalidade dos caixilhos. Tratou-se, pois, de uma intervenção inovadora do ponto de vista metodológico, muito refinada, e que demonstrou concretamente que a problemática do restauro de uma obra do século 20 não é tão diferente daquela que se encontra operando nas obras antigas, desde que se enfrente a sua complexidade com o mesmo rigor teórico, metodológico e científico.

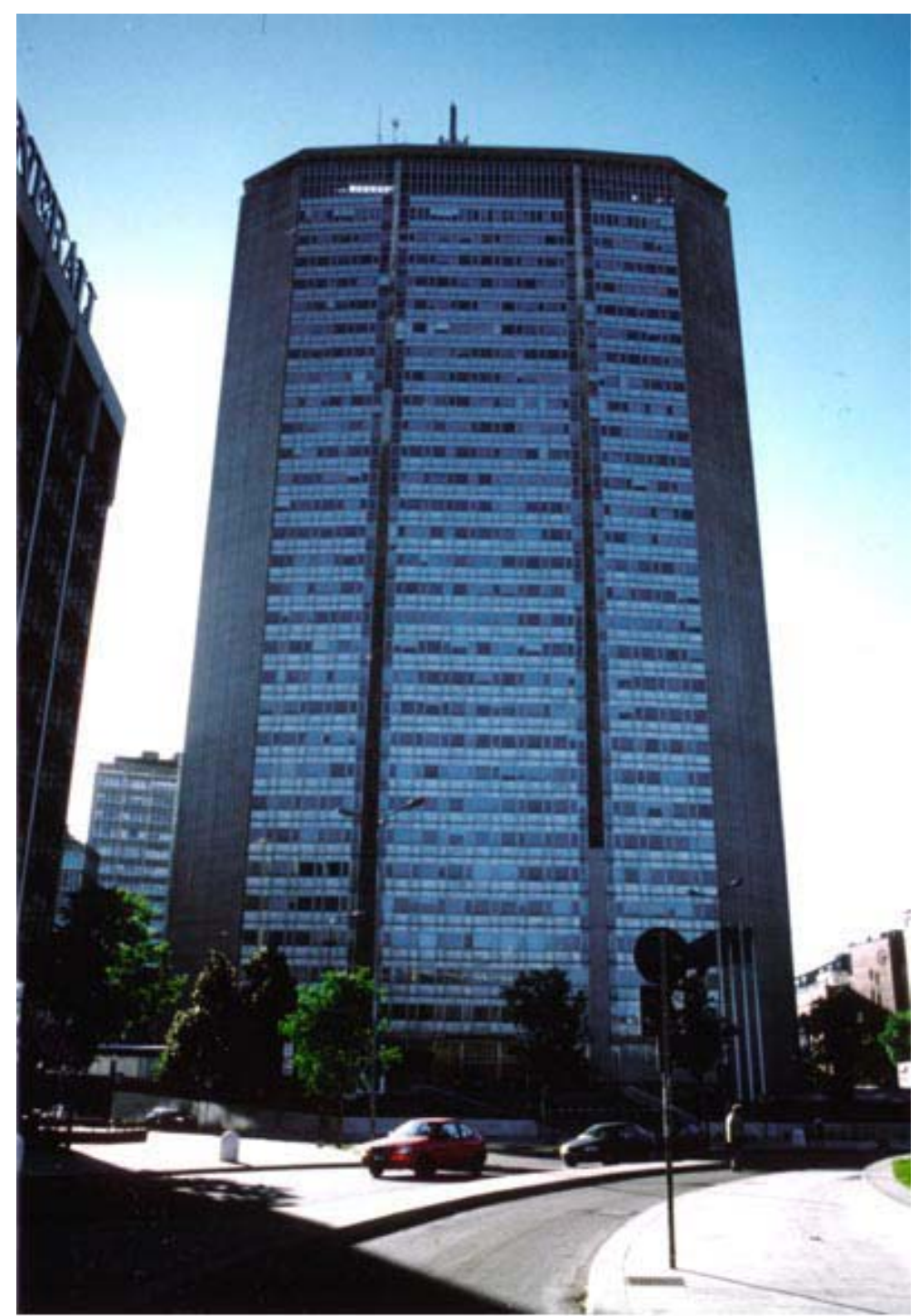

Figura 1 - Edificio Pirelli, Mild̃o (autores: Ponti, Fornaroll, Rosselli, Valtolina, Dell'Orto, Nervi, Danusso; 1956-1961). Estado do edificio em 1998. Fotografia: autora. 


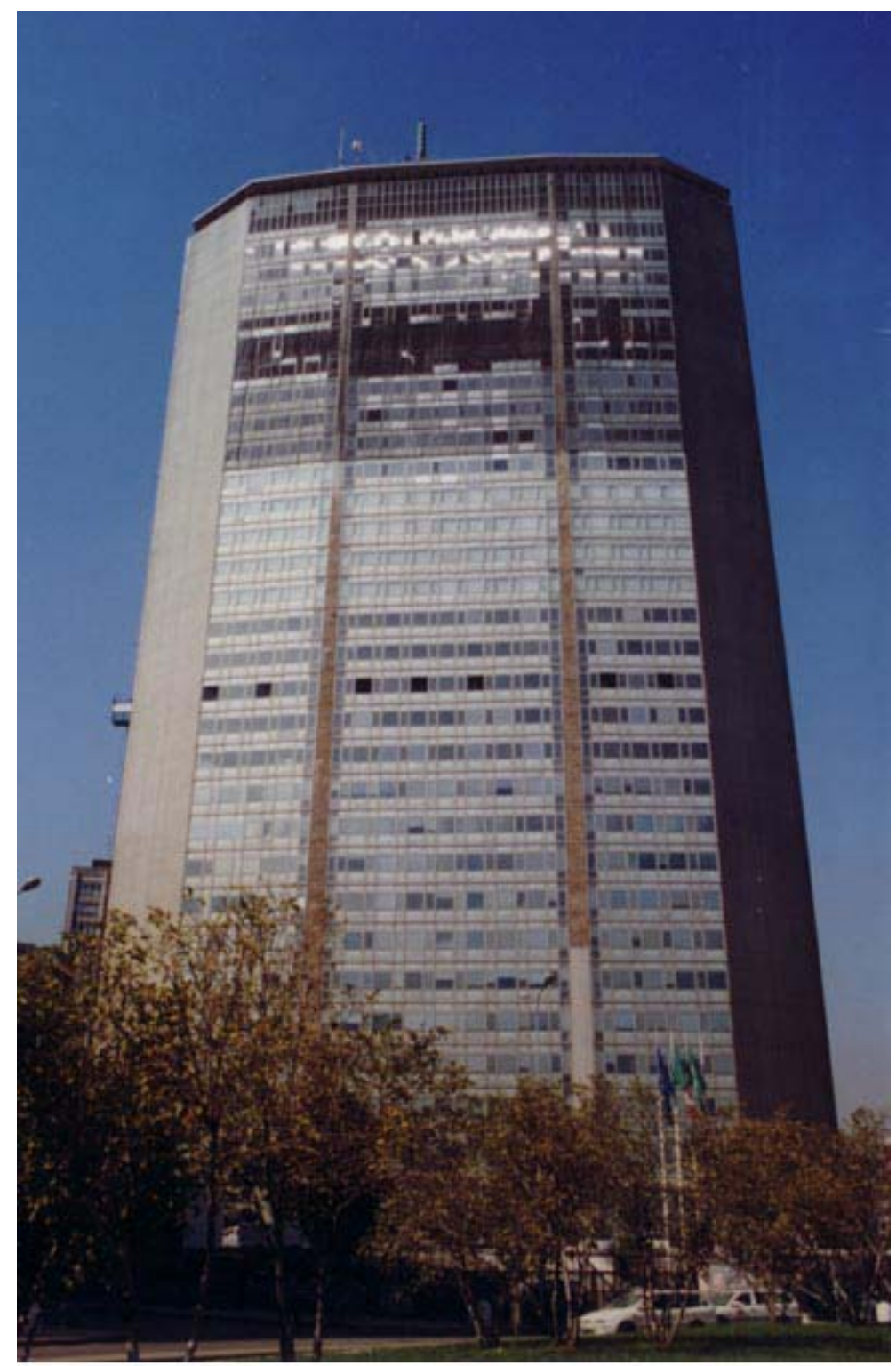

Figura 2 - Edificio Pirelli, Milão. Danos causados às fachadas do edificio pelo impacto do monomotor em 18 de março de 2002, Fotografia: autora.

A operação feita no Pirelli distingue-se da prática repristinatória correntemente exercitada nos edifícios do século 20 - e ainda mais freqüente nas fachadas contínuas - na Itália e no exterior. Algumas intervenções recentes feitas em renomados edifícios altos estadunidenses e europeus são, com efeito, particularmente significativas e emblemáticas das posturas mais difusas quando a aproximação histórico-crítica à obra é parcial ou de todo ausente.

A exigência de adequar os arranha-céus construídos entre os anos 1950 e 1970 às imposições do uso, às normas de segurança e aos atuais padrões habitacionais, nasce no final dos anos 1980, quando o estado de conservação das fachadas contínuas que os revestem se mostra cada vez mais precário. As condições e as 
causas de degradação parecem análogas em numerosos edifícios, pois as tipologias construtivas empregadas no imediato pós-guerra para realizar as fachadas contínuas são praticamente estandardizadas (3), distinguindo-se, de modo prevalente, pela qualidade do detalhamento, dos materiais empregados e pela solução estrutural adotada. Com efeito, as manifestações de degradação mais difusas são, além do mais, dependentes da perda de resistência dos caixilhos em relação aos agentes atmosféricos, e das ancoragens em relação à estrutura portante do edifício (4); no primeiro caso, por causa do envelhecimento das guarnições e seladores entre as armações e os painéis, realizados com materiais derivados do látex, na época ainda experimentais; no segundo, pelo diverso comportamento elástico dos materiais que constituem a fachada em relação à estrutura (5).

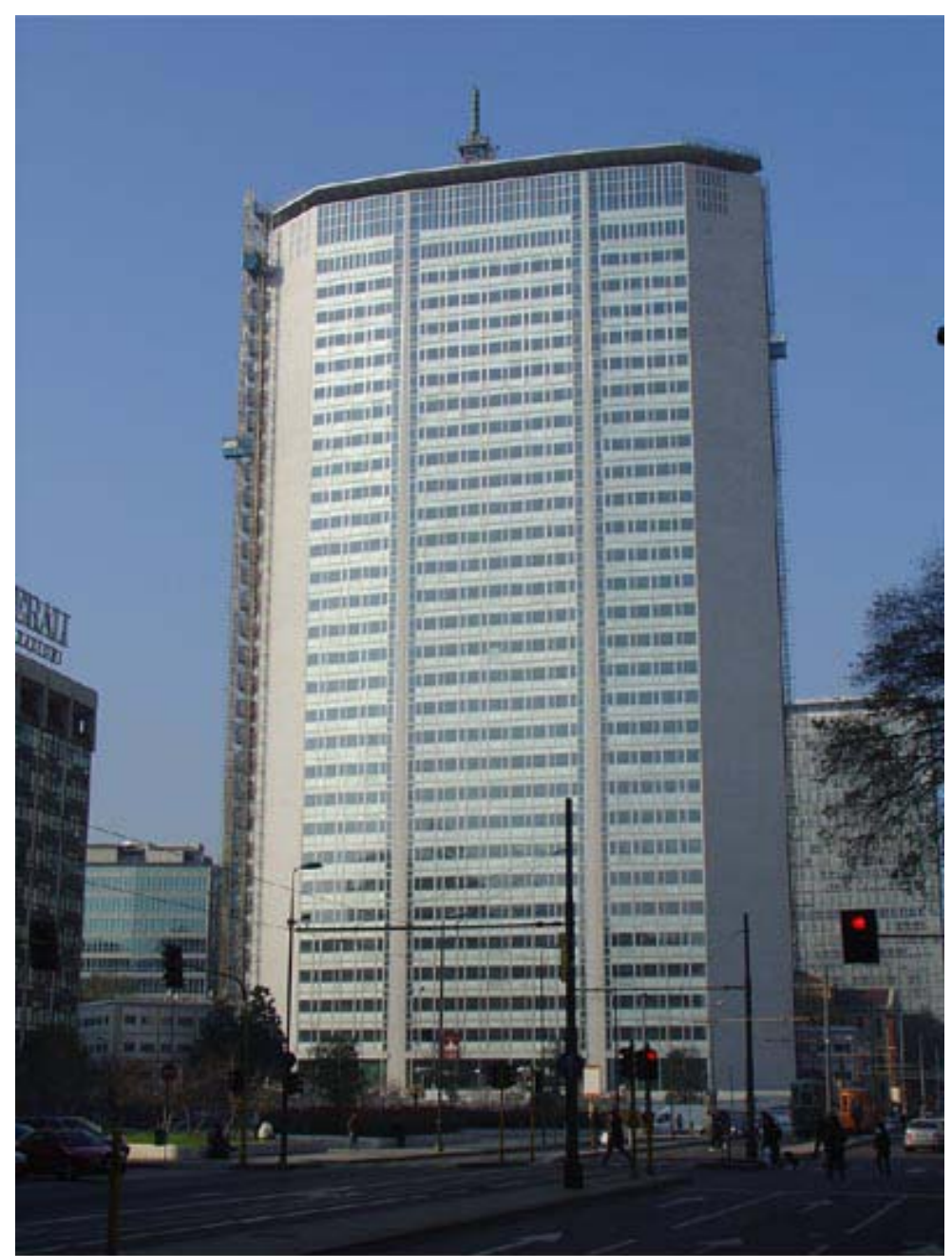

Figura 3 - Edificio Pirelli, Milão. Edificio em março de 2004, depois da conclusão dos trabalhos de restauro das fachadas. Fotografia: autora.

Grande parte das intervenções feitas com essa finalidade, na Europa e nos Estados Unidos, demonstra que a atenção para com esse tipo de construção se voltou 
prevalentemente à imagem e à funcionalidade do invólucro, e não às soluções construtivas e tecnológicas, complexas e freqüentemente experimentais, desenvolvidas para permitir que os arranha-céus crescessem em altura, garantindo sua estabilidade (6). Um aspecto irrenunciável do significado desses edifícios reside, com efeito, na tipologia construtiva das fachadas contínuas curtain wall em que se concentra a qualidade do detalhe tecnológico, do desenho industrial, da capacidade empreendedora, dos materiais e do êxito formal. No entanto, na maior parte dos casos, o seu valor testemunhal foi subjugado por exigências de caráter econômico e funcional que levaram a substituir sistematicamente as partes originais para restituir funcionalidade e eficiência aos elementos e, ao mesmo tempo, para recuperar a imagem primitiva, recorrendo a uma reprodução à l'identique: por um lado, portanto, tende-se a repristinar o aspecto exterior, por outro, a "corrigir o erro" técnico.

Um dos primeiros exemplos feitos em fachadas curtain wall dos anos 1950 remonta ao início dos anos 1990 e refere-se à Lever House de Nova York (7), projetada e realizada em 1952 pelo escritório Skidmore Owings \& Merrill, com a colaboração de Gordon Bunshaft. O arranha-céu, um bloco retangular de dezoito andares circundado por uma série de corpos mais baixos onde foram concentrados os ambientes de representação, foi realizado experimentando um novo tipo de fachada contínua, sucessivamente utilizado em muitos outros edifícios de Nova York. O invólucro externo, estruturalmente independente da ossatura portante do edifício, era constituído por uma armação metálica com montantes e pares de travessas, nos quais eram fixados os painéis. Estes últimos eram isolados na parte voltada ao interior, enquanto a parte externa possuía caneluras que serviam de lacrimais para a água pluvial. Do ponto de vista estético, a característica mais evidente constituía no efeito espelhado dos painéis envidraçados, nos quais se refletiam os edifícios circunstantes da Park Avenue que, no momento de sua realização, era, ademais, constituída por edifícios de altura média de linguagem oitocentista. A Lever House representou uma verdadeira fratura no tecido urbano regular de Manhattan e assinalou o início de um irrefreável processo de substituição dos edifícios antigos por arranha-céus de caráter vanguardista (Figura 4). 


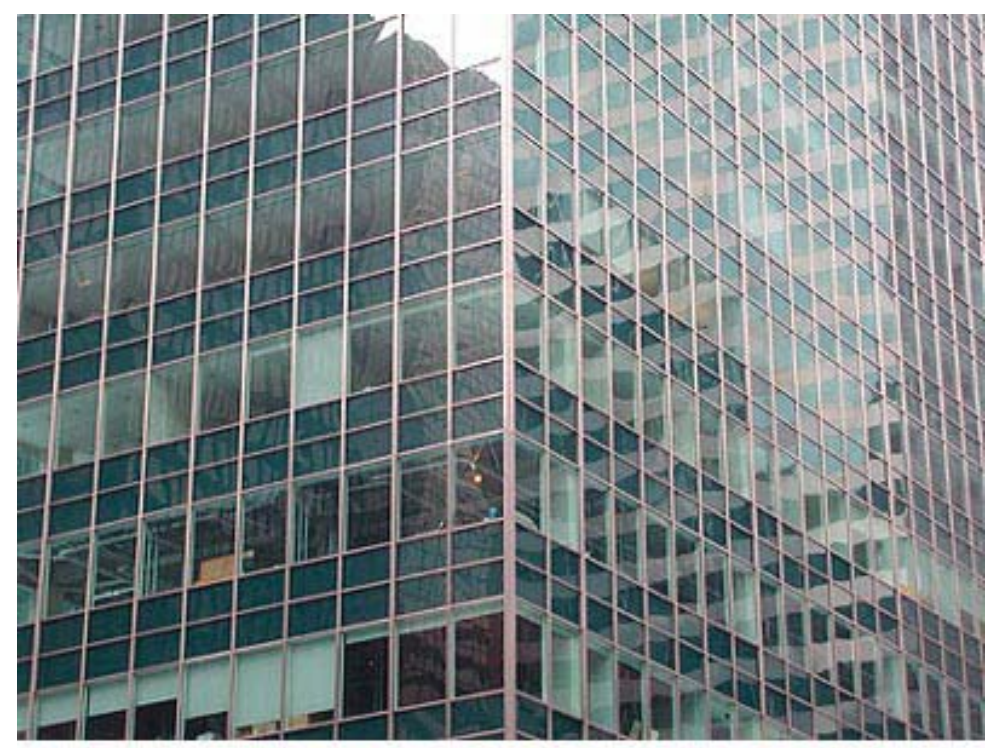

Figura 4 - Lever House, Nova York (autores: Skidmore, Owings \& Merrill com Gordon Bunshaft; 1952). Edificio depois da intervençāo de repristinação do invólucro externo. Fotografia: autora.

Poucos anos depois de sua construção, o arranha-céu começou a mostrar evidentes sinais de degradação, dado que o tipo de selador que garantia a resistência à água e ao ar do curtain wall, inovador e aplicado com um sistema experimental, havia envelhecido precocemente e permitia que a água se infiltrasse e atingisse as partes metálicas, dando origem a um pernicioso processo de oxidação. A radiação solar causava consideráveis expansões na armação metálica que, tendo um coeficiente de dilatação térmica muito superior ao das partes envidraçadas, induzia tensões que causavam fraturas e fissurações em vários pontos, especialmente em correspondência às partes envidraçadas, e uma notável concentração de esforços nas juntas de ancoragem do curtain wall na estrutura portante; ademais, a intensa radiação solar, potencializada pelas superfícies completamente envidraçadas do edifício, tornava muito incômodas as condições microclimáticas dos interiores, em especial nos meses de verão.

Por alguns anos tentou-se remediar os danos através de pequenas obras de manutenção e de substituições pontuais; os vidros quebrados eram substituídos de modo sucessivo, mas as placas utilizadas nas trocas não eram da cor exata das originais, de modo que essas substituições sobressaíam e privavam as fachadas do arranha-céu do caráter uniformemente espelhado, considerado um seu aspecto peculiar. 
No início dos anos 1990, o escritório Skidmore Owings \& Merrill foi encarregado de realizar um projeto que resolvesse definitivamente os problemas de degradação do arranha-céu, então em estado precário. O projeto previa a repristinação do aspecto originário do edifício, com particular cuidado para com a qualidade refletora das superfícies, mesmo a custo de se fazer extensas substituições. Depois de se ter avaliado a opção de reparar os painéis originais, preferiu-se substituir de modo sistemático todas as ancoragens do curtain wall, todos os painéis, a armação metálica e a ferragem de aço inoxidável, conservando apenas alguns montantes ainda em boas condições. Apesar das substituições e repristinação completa das superfícies espelhadas, a imagem do edifício mudou irremediavelmente em relação àquela original: o efeito estrondoso buscado por Skidmore Owings \& Merrill nos anos 1950 - obtido através de um volume de formas puras e com superfícies perfeitamente refletoras e homogêneas, sobre as quais se espelhavam, em polêmica contradição, as construções circunstantes de estilo art nouveau - estava agora definitivamente perdido por causa da substituição paulatina dos edifícios da Park Avenue por arranha-céus com curtain walls que hoje diluem muito o significado vanguardista da Lever House. Com efeito, o motivo que induziu ao descarte da solução de se conservar os painéis originais, substituindo apenas aqueles ineficientes, foi conseqüência do valor "icônico" desde sempre atribuído à Lever House e do papel de marco que possuía na perspectiva da Park Avenue. A intervenção de substituição integral, desse modo, não foi determinada por causas intrínsecas aos painéis ou à sua degradação, mas apenas por uma questão de imagem e, talvez, por uma certa incapacidade, da opinião pública e dos encarregados, em aceitar que o aspecto do arranha-céu envelhecesse; o fato de se ter confiado a intervenção aos próprios autores do edifício, ademais, confirma a intenção de atualizar os desempenhos técnicos do edifício, além de repristinar sua conformação originária.

Nos mesmos anos foi feita a intervenção na Thyssen Haus de Düsseldorf, edifício alto com fachadas contínuas projetado e realizado, entre 1955 e 1960, por Helmut Hentrich e Hubert Petschnigg (8); o edifício é composto por três corpos, ditos lâminas - donde o apodo Dreischeibenhaus - com seis metros de largura e noventa e seis metros de altura. A estrutura portante é de aço: as fachadas principais são constituídas por painéis opacos e envidraçados, enquanto os lados menores são 
vedados por elementos pré-fabricados de cimento revestidos por painéis metálicos "remanit", uma liga de alumínio bastante leve, mas durável. Quando da sua realização, o projeto estrutural do edifício foi considerado uma verdadeira obra-prima de seu gênero, pela relação entre a excepcional esbelteza da estrutura, a extensão das superfícies da fachada (cerca de $8.000 \mathrm{~m}^{2}$ ) e as forças imensas a que deveria resistir por causa do vento.

No skyline da cidade de Düsseldorf, o prédio destaca-se do resto das construções pela forma e pelas dimensões e é, ainda hoje, um dos arranha-céus mais famosos na Alemanha e na Europa. A construção tornou-se, assim, um símbolo da recuperação econômica alemã no pós-guerra, além de ser um marco no processo de americanização das cidades européias.

Poucos anos depois da construção, porém, começaram a ser necessárias intervenções de reparo e pequenas substituições, seja nas fachadas, seja nas instalações, intimamente conexas entre si. Em meados dos anos 1980 as condições do arranha-céu eram a tal ponto precárias que tornaram necessária uma intervenção radical, dado que os painéis da fachada não mais garantiam condições de conforto nos interiores: por causa das expressivas dilatações devidas às grandes amplitudes térmicas, os caixilhos haviam perdido a resistência aos agentes atmosféricos, resultando em infiltrações d'água e condensação no interior dos painéis, que deram origem a processos de corrosão que estavam comprometendo a resistência das ancoragens na estrutura portante. Por conseguinte, também as instalações - de combate a incêndios e de climatização - requeriam uma adequação geral.

Em 1987 o projeto de recuperação do edifício foi confiado ao mesmo escritório que o havia realizado nos anos 1950, solicitando-se a colaboração de Hentrich que, apesar da idade, havia cuidado pessoalmente do projeto e da construção do arranha-céu. De início, foram estudados os documentos e os desenhos feitos para a execução da obra; contemporaneamente, fez-se um levantamento pormenorizado dos problemas existentes na construção, registrando sua localização e intensidade. Os desempenhos técnicos e estruturais das fachadas foram depois confrontados com os padrões impostos pelas normas vigentes, mostrando-se inevitavelmente ineficazes e obsoletos. A intervenção foi, portanto, enfrentada como uma revisão 
completa dos detalhes técnicos e construtivos, evitando quaisquer mudanças de suas características formais. A operação mais consistente foi voltada ao refazimento integral das fachadas: os novos painéis de vidro, redesenhados retomando a forma e a partição dos originais, foram realizados com modernos expedientes tecnológicos que satisfazem aos atuais requisitos. A nova armação metálica é constituída por uma grelha de perfis de alumínio, descontínua apenas nas juntas de dilatação térmica e nas guias das cabines para a manutenção externa, enquanto os painéis envidraçados foram realizados com modernos vidros duplos, com as placas obtidas através do processo de flutuação, com uma película especial de revestimento que melhora seu desempenho; no interior dos painéis foram inseridas canaletas para as instalações de climatização. Das fachadas originais foram conservados, desse modo, apenas o revestimento das faces menores das três "lâminas", realizado com painéis "remanit", desmontados, verificados e recolocados em seu lugar, por estarem ainda em boas condições de conservação.

Essa intervenção demonstra como a instância funcional pode causar dano ao valor histórico-arquitetônico do edifício que, por oportunismo e por tradição, se tende a fazer coincidente com o aspecto externo, sem prestar atenção aos detalhes estruturais e tecnológicos autênticos, mesmo se encobertos. Também nesse caso, para a escolha repristinatória, por certo contribuiu a decisão de atribuir a operação aos autores do edifício, normalmente inclinados a desenvolver o próprio projeto para melhorá-lo e para corrigir os problemas técnicos surgidos com o tempo, confiando o êxito da operação à aplicação de tecnologias avançadas.

Um tipo de intervenção diverso, mas gerado por uma aproximação comum aos outros exemplos, foi o adotado para a ex-torre da Alitalia no EUR, em Roma, realizada em 1967 pelo escritório dos milaneses Valtolina, Rusconi e Clerici. As premissas para a operação são, novamente, contidas na escolha dos comitentes, a sociedade IBM, nova proprietária do edifício. Com efeito, procurando ali instalar a própria sede, no início dos anos 1990 a IBM voltou-se a um arquiteto de marcante criatividade, Gino Valle, para repensar o edifício (Figura 5). A incumbência é sincera e lucidamente acolhida como radical transformação, desejada e buscada, de um edifício funcional e moderno que, como tal, é condenado à obsolescência; Valle, sentindo-se livre de quaisquer limites em relação àquele legado, posto que "talvez 
não tenha jamais sido uma verdadeira arquitetura" e "confortado pela convicção que a arquitetura sempre evoluiu através da reciclagem das construções" (TRASFORMAZIONE, 1994, p.60), quis, assim, transformar a imagem sedimentada da torre segundo uma aproximação puramente criativa.

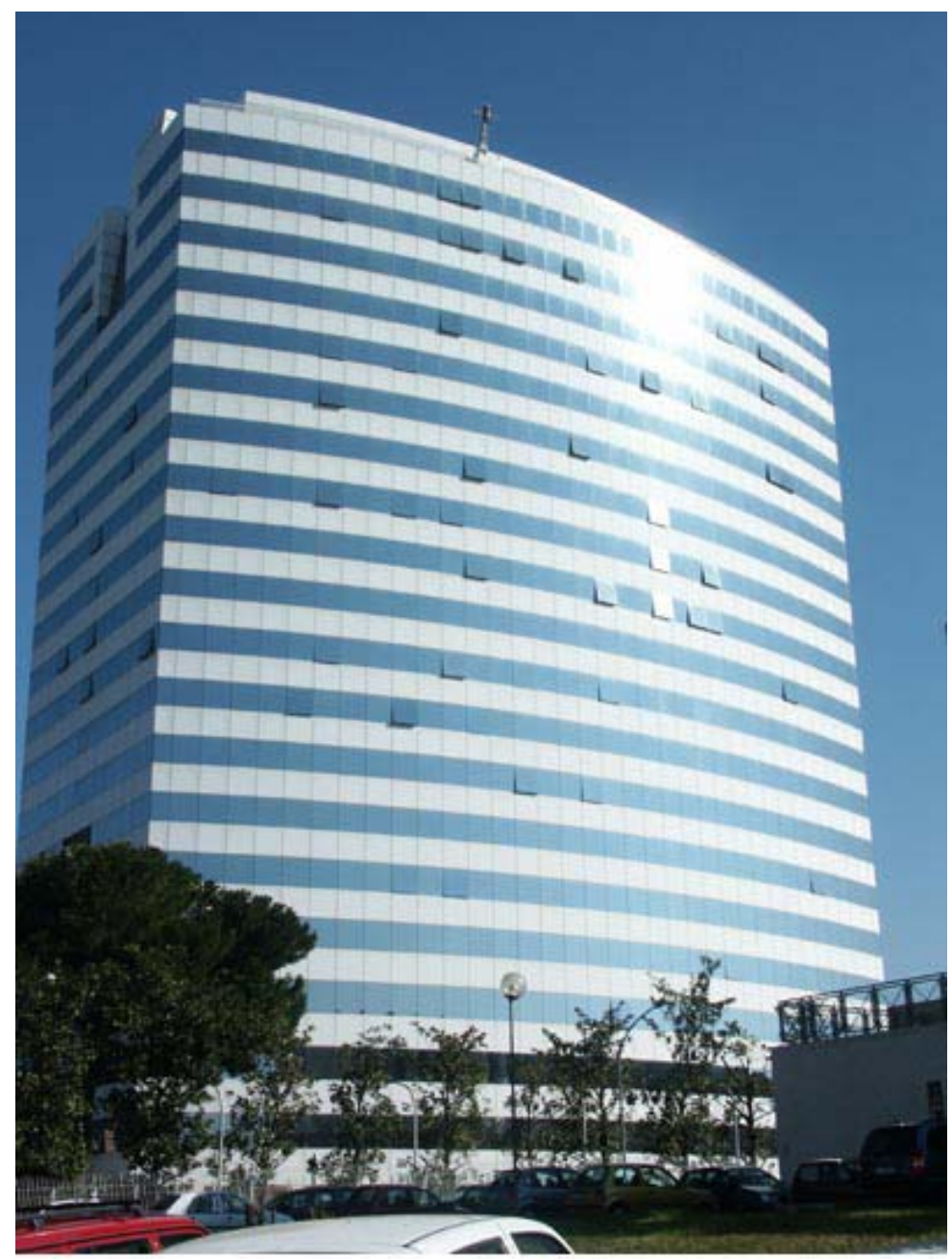

Figura 5 - Ex-torre Alitalia, depois sede da IBM, atual sede INAIL, Roma - EUR (autores: Rusconi, Clerici; 1967). O edificio após intervenção de restyling projetada por Gino Valle. Fotografia: autora.

A intervenção, executada entre 1985 e 1994 (9), consistiu na renovação integral do edifício, excluindo-se as partes estruturais e a circulação vertical, através de formas e materiais novos no invólucro externo e da reorganização da distribuição interna. A nova fachada, semi-portante e curvilínea, é formada por painéis isolantes de "alucobond" alternados com vidros duplos espelhados; graças a uma futurista armação telescópica, os painéis permanecem independentes, assistidos nos respectivos movimentos e dotados de características de isolamento térmico e acústico. O resultado da operação é certamente fascinante e de forte impacto visual, além de tecnicamente bem-sucedido. E, no entanto, a ex-torre Alitalia, considerada 
tout court como tendo uma forma "anônima e um pouco deprimente", com as suas superfícies de ritmo fragmentário, representava um significativo influxo, sobre as elaborações da época, exercitado pela "forma finita" idealizada por Gio Ponti para o arranha-céu da Pirelli de Milão; talvez tivesse merecido ser recordado por aquilo que era, ou seja, um elo menor na "cadeia evolutiva" dos edifícios em altura.

As tentativas para elaborar uma história da arquitetura da segunda metade do século 20, com exceção de alguns ensaios recentes, parecem fixadas numa leitura lingüística e formal das obras ou da produção dos grandes autores, que exclui a história das obras como expressão da cultura construtiva, tecnológica e sócioeconômica. Tende-se, com efeito, a considerar a produção arquitetônica recente uniforme e concatenada no interior de uma corrente unidirecional, quando, na verdade, ela se mostra complexa, variada e avessa a simplificações e categorizações.

Deveria tratar-se, em suma, de enfrentar um problema de impostação históricocrítica de obras muito recentes que, nos casos mais afortunados, ocupam um lugar no imaginário das formas e dos "estilos" dos arquitetos contemporâneos, mas não ainda na história da cultura arquitetônica, com exceção de alguns casos isolados (10). A excepcional restauração das fachadas do Pirelli, assim como a longa experiência da restauração do antigo, demonstra que apenas "entrando dentro" da arquitetura e analisando-a de perto na sua realização efetiva, é possível adquirir consciência do seu valor e evidenciar plenamente sua qualidade estética, funcional, social, ética e cultural, mas também sua fragilidade e seu valor testemunhal; um significado, ademais, que deve ser buscado além das fronteiras nacionais para se perceber os influxos e repercussões que qualquer obra significativa produziu e que representam uma de suas mensagens mais significativas. Trabalho este apenas em aparência facilitado pela proximidade temporal que, ao contrário, ilude e deriva para os lugares-comuns; a bem dizer, o processo crítico revela-se mais árduo para uma obra recente do que para uma antiga. Mas somente através dele se desenvolve uma atenção "conservativa" adequada e uma abertura criativa para o projeto - que não é a livre transformação ou inovação, mas é interna à obra - que conduza à individuação de novos valores ou estratégias interpretativas das obras preexistentes, e não à criação de novos objetos. 
A aproximação crítica representa, portanto, a única via metodologicamente correta para indagar as obras preexistentes e para definir a extensão da intervenção sobre elas, tendo em vista sua conservação e transmissão ao futuro, como quer a restauração. Por essa via também a restauração do novo pode instituir uma profícua relação com a história e tornar-se, em si, obra de arte; até mesmo uma arte da "ausência", da "renúncia", segundo a definição de Bruno Reichlin (1997/1998), que acolha em si a competência científica, a capacidade crítica e o esforço criativo exigidos pela conservação.

A restauração do moderno coloca condições complexas e articuladas, que requerem uma leitura numa chave problemática, jamais simplista, capaz de enfrentar a árdua formulação de "juízos de valor" sobre o novo e as inevitáveis dificuldades operacionais que são encontradas num contexto ligado a questões técnicas, funcionais e econômicas, talvez até mesmo mais do que no caso do antigo. Uma atividade crítica intensa, sensível, coerente e informada dos princípios de restauração constitui o único instrumento para resolver os obstáculos de caráter interpretativo e de execução que comporta a intervenção no novo; ao contrário, tende-se a simplificar, banalizando, e a renunciar à solução conservativa por princípio, fato que, por si só, denuncia uma certa confusão sobre o significado e as finalidades da intervenção. São exceções alguns núcleos isolados de elaboração teórica, refinada e sensível aos temas de restauro, encontráveis em alguns âmbitos restritos de pesquisa, e os êxitos convincentes de algumas intervenções iluminadas que, além de tudo, demonstram que negar a possibilidade de conservação do moderno é injustificado e sem fundamento teórico. Constitui a prova "experimental" disso o processo de aproximação crítico-cognitivo efetuado quando da intervenção nas fachadas do arranha-céu da Pirelli que, como alternativa à opção substitutiva, induziu a percorrer a via da verdadeira restauração, demonstrando, assim, concretamente, a aplicabilidade de seus princípios e de seu método também em obras não antigas.

\section{Notas}


(1) Este texto foi elaborado para a reunião científica "Antico e nuovo, Architetture e architettura" realizada na Faculdade de Arquitetura do IUAV, de Veneza, de 31 março a 3 de abril de 2004. (N. da T.)

(2) A restauração das fachadas do Pirelli foi coordenada por uma comissão técnico-científica altamente gabaritada, nomeada pelo Governo da Região Lombardia, composta por Pietro Petraroia, Maria Antonietta Crippa, Carla Di Francesco e Giovanni Carbonara. Essa comissão coordenou os trabalhos e estabeleceu as diretrizes a serem seguidas, fundamentando-se no intercâmbio constante com equipe multidisciplinar - de que participou Simona Salvo - de amplo espectro, que desenvolveu estudos aprofundados sobre os vários aspectos concernentes à restauração da obra. Ver a respeito em SALVO, Simona. A restauração do arranha-céu Pirelli: a resposta italiana a uma questão internacional. Pós. Revista de Pós-Graduação em Arquitetura e Urbanismo da FAU-USP, n.19, p.201-210, 2006. (N. da T.)

(3) Os três tipos principais de curtain wall se distinguem com base no método de fabricação e de montagem: o stick system, com montantes e travessas e com painéis aplicados a seco, representa o sistema mais comum, adotado também no arranha-céu Pirelli; o unit system, a "célula pré-fabricada"; o unit and mullion system, um sistema misto, com montantes e travessas e elementos de ancoragem na estrutura portante pré-fabricados.

(4) A esse respeito ver: KELLEY, S. J.; JOHNSON, D. K. The metal and glass curtain wall: the history and diagnosis. In: CUNNINGHAM, A. Modern movement heritage. Londres / Nova York: Spon, 1998. p.77-87.

(5) O envelhecimento das superfícies metálicas dos perfis dos caixilhos e a degradação ou a ruptura dos painéis opacos e envidraçados se apresentam de modo menos grave ou, antes, como conseqüência das já citadas causas de degradação.

(6) Sobre esse assunto, ver: SALVO, S. II restauro del grattacielo Pirelli. Una questione internazionale, un intervento italiano. In: GRATTACIELO Pirelli: indagini sulle fonti documentarie e sulle esperienze internazionali. Milão: Assessorato per le Identità, le Culture e le Autonomie della Regione Lombardia, 2002.

(7) Cf. a esse respeito: PRUDON, T. M. H. Restoring 20th century skyscrapers in New York: Woolworth Building, Chrysler Building, Lever House. In: LIPP, K. M. (Org.). Konservierung der moderne? Über den umgang mit den zeugnissen der architekturgeschichte des 20. Jahrhunderts. Atas do congresso do comitê alemão do Icomos, Leipzig, 31 de out. - 2 de nov. 1996. Munique: Icomos, 1998. p.69-75.

(8) Cf. a respeito: ZERRES, E. A curtain wall replaced from head to toe. The Thyssen Haus in Düsseldorf (1957). Docomomo Journal. Curtain wall refurbishment, n.15, p.54-57, 1996; FÜRST, T. M. Das Thyssen Haus in Düsseldorf: die modernisierung eines nachkriegsmonuments. In: LIPP, K. M. (Org.). Konservierung der moderne? Über den umgang mit den zeugnissen der architekturgeschichte des 20. Jahrhunderts. Atas do congresso do comitê alemão do Icomos, Leipzig, 31 de out. - 2 de nov. 1996. Munique: Icomos, 1998. p. 77-89.

(9) Cf. GINO Valle. Trasformazione della Torre Alitalia a Roma Eur. 1993-1996. Anfione e Zeto, n.12, 1999. Número monográfico. SCURI, P. Edifici per uffici: a Roma la Torre IBM. La ristrutturazione integrale della torre IBM, progetto arch. Gino Valle, Ufficiostile, n.6, p.54-61, 1995. A intervenção, projetada por Gino Valle, foi dirigida pelo arquiteto Carlo Costantini. 
(10) Entre eles, recorda-se: DAL CO, F. (Org.). Storia dell'architettura Italiana. II secondo Novecento. Milão: Electa, 1997.

\section{Referências Bibliográficas}

DAL CO, F. (Org.). Storia dell'architettura Italiana. II secondo Novecento. Milão: Electa, 1997.

FÜRST, T. M. Das Thyssen Haus in Düsseldorf: die modernisierung eines nachkriegsmonuments. In: LIPP, K. M. (Org.). Konservierung der moderne? Über den umgang mit den zeugnissen der architekturgeschichte des 20. Jahrhunderts. Atas do congresso do comitê alemão do Icomos, Leipzig, 31 de out. - 2 de nov. 1996. Munique: Icomos, 1998. p. 77-89.

GINO Valle. Trasformazione della Torre Alitalia a Roma Eur. 1993-1996. Anfione e Zeto, n.12, 1999. Número monográfico.

KELLEY, S. J.; JOHNSON, D. K. The metal and glass curtain wall: the history and diagnosis. In: CUNNINGHAM, A. Modern movement heritage. Londres / Nova York: Spon, 1998. p.77-87.

PRUDON, T. M. H. Restoring 20th Century Skyscrapers in New York: Woolworth Building, Chrysler Building, Lever House. LIPP, K. M. (Org.). Konservierung der moderne? Über den umgang mit den zeugnissen der architekturgeschichte des 20. Jahrhunderts. Atas do congresso do comitê alemão do Icomos, Leipzig, 31 de out. 2 de nov. 1996. Munique: Icomos, 1998. p.69-75.

REICHLIN, B. Introduzione. Faces (La sauvegarde du moderne), n. 42/43, p. 9, 1997/1998. Número monográfico.

SALVO, S. II restauro del grattacielo Pirelli. Una questione internazionale, un intervento italiano. In: GRATTACIELO Pirelli: indagini sulle fonti documentarie e sulle esperienze internazionali. Milão: Assessorato per le Identità, le Culture e le Autonomie della Regione Lombardia, 2002.

A restauração do arranha-céu Pirelli: a resposta italiana a uma questão internacional. Pós. Revista de Pós-Graduação em Arquitetura e Urbanismo da FAU-USP, n.19, p.201-210, 2006.

SCURI, P. Edifici per uffici: a Roma la Torre IBM. La ristrutturazione integrale della torre IBM, progetto arch. Gino Valle. Ufficiostile, n.6, p.54-61, 1995.

TRASFORMAZIONE della torre IBM a Roma. Casabella, n. 622, p. 60, 1994.

ZERRES, E. A curtain wall replaced from head to toe. The Thyssen Haus in Düsseldorf (1957). Docomomo Journal. Curtain wall refurbishment, n.15, p.54-57, 1996.

* Arquiteta. Especialista em restauro de monumentos e doutora pela Universitá degli Studi di Roma "La Sapienza". Docente da Universitá degli Studi di Roma "La Sapienza" e da Faculdade de Arquitetura da Universidade de Ascoli Piceno. 
** Arquiteta. Doutora pela FAU-USP. Professora do Departamento de História da Arquitetura e Estética do Projeto da FAU-USP. 